\title{
China's Interest Rate Marketization and Interest Rate Transmission Mechanism: Historical Experience and Enlightenment
}

\author{
Xiuli Cui, PhD \\ School of Economics \\ Central University of Finance and Economics \\ 39 XueYuan South Road \\ HaiDian District, Beijing, China
}

\begin{abstract}
Interest rate marketization and interest rate transmission mechanism have complementary internal relations. Analysis of interest rate marketization reform process helps to understand the evolution logic of interest rate transmission mechanism, and interest rate transmission mechanism construction is related to China's monetary policy operation framework transformation.At present, the construction of interest rate transmission mechanism of China's monetary policy still needs to be further promoted. The benchmark interest rate of deposits has not been abolished, the ability of financial institutions to price interest rates is not strong, and the market benchmark interest rate system is imperfect, which restricts the smooth flow of interest rate transmission mechanism.This paper summarizes the evolution and characteristics of interest rate transmission mechanism in different stages of China's interest rate marketization reform from the two scenarios of interest rate dual-track system and interest rate integration, and forms and evolves the money market interest rate to bond market interest rate and deposit-loan interest rate transmission mechanism. The obstacles are analyzed, revealing the logic law implied by the interest rate marketization reform and the evolution of the interest rate transmission mechanism, providing a reference for improving the interest rate transmission mechanism in the future. At the same time, combining with the current reality of China's interest rate transmission mechanism, this paper proposes to strengthen and give play to the role of interest rates transmission mechanism.This paper believes that interest rate marketization is the source of interest rate transmission mechanism. China's interest rate marketization reform has achieved great success at the institutional level, but still exists in the financial institutions' own pricing power, the construction of SME financing channels, and the construction of market benchmark interest rate system. Obstructing the smooth flow of the interest rate transmission mechanism, it should be regarded as a key segment of the interest rate transmission mechanism in the future.
\end{abstract}

Keywords: Interest rate, Marketization, Transmission mechanism, Evolution

\section{Introduction}

China's interest rate transmission mechanism has become increasingly sound with the deepening of the interest rate market reform, and the interest rate system reform has promoted the improvement of the interest rate transmission mechanism.

Since the release of the interbank lending rate in 1996 and the liberalization of the deposit interest rate limit in 2015, the 20-year progressive interest rate liberalization reform has achieved a phased goal. The financial environment in which the interest rate transmission mechanism is located has gradually shifted from financial suppression to finance. Liberalization transformation, in this process, China's interest rate market-based pricing mechanism and interest rate transmission mechanism are gradually improved, the correlation between real interest rate and real economic growth is significantly enhanced, the dividend of interest rate marketization reform is fully released, interest rate marketization reform is interest rate. The construction of the transmission mechanism has laid a solid foundation.In the future, the construction of interest rate transmission mechanism will be promoted from diffuse irrigation to drip irrigation to improve the precise transmission and regulation effect of interest rate policy.

As China's financial market becomes more mature, the resilience of the interest rate transmission mechanism will gradually increase. However, the interest rate marketization reform only provides an external financial policy and market environment. To improve the interest rate transmission mechanism, it is necessary to strengthen the financial institutions' own capacity building to strengthen their adaptability and influence to the financial market.At present, China's interest rate liberalization reform still needs to be pushed forward, and the pricing power of financial institutions still needs to be further improved. In addition, financial innovation keeps emerging, hedging of interest rate policies continues to exist, and interest rate transmission mechanism generally shows a trend of diminishing marginal effect. 
To further improve China's interest rate transmission mechanism must be based on the current reform and development, not from history, should be along the track of evolution of interest rates transmission mechanism, combined with the current and future financial market conditions, prudential soundness to continuously optimize the interest rate transmission mechanism, guarantee balanced interest rate transmission mechanism reform direction and rhythm, boosting our country monetary policy successful transition from quantitative to price operation framework.

Based on this consideration, this paper attempts to follow the historical trajectory and context of China's interest rate marketization reform, to investigate the generation, evolution and evolution of the interest rate transmission mechanism, in order to find inspiration for solving the pain, difficulty and blocking point of the interest rate transmission mechanism in the deep water area of reform.

\section{Literature Review}

Since 1996, China has started a progressive interest rate marketization reform process (Wan Quan and Sun Bin, 2012).In 1996, the central bank abolished the upper limit of the interbank lending market interest rate, and firstly released the interbank lending market interest rate (Fan Fangzhi,2006), marking the official start of the interest rate liberalization reform in China.Subsequently, it liberalized the bond repurchase rate and cash bond transaction rate in 1997, the discount rate and rediscount rate in 1998, the issuance rate of policy-based financial bonds in 1999, the agreement rate for large term deposits of insurance companies in the same year, and the foreign currency loan rate in 2000 (ShenQiyun and Wen Ming,2004).In 2004, the loan interest rate ceiling and the deposit interest rate ceiling were completely abolished, and the foreign currency deposit interest rate was fully liberalized (Zhao Shengmin and Chen $\mathrm{Yu}$,2019).In July 2013, the People's Bank of China abolished the lower limit of the loan interest rate of financial institutions. In 2015, the upper limit of the deposit rate of financial institutions was abolished. At present, the reform of interest rate liberalization has been basically completed(Chen Yulu,2018).The interest rate marketization for nearly 20 years has created a good institutional environment and financial environment for the construction and improvement of China's interest rate transmission mechanism, and also provided the necessary conditions for the price structure of China's monetary policy operation framework.

Without interest rate liberalization reform, the effectiveness of interest rate transmission mechanism cannot be discussed, but interest rate liberalization is not equal to the effectiveness of interest rate transmission mechanism.The connotation of interest rate liberalization includes two aspects: the liberalization of interest rate control and the establishment of market-oriented interest rate pricing and control mechanism. The liberalization of regulated interest rate does not mean the final completion of interest rate liberalization, and the reform of interest rate liberalization still needs to be further promoted (Liu mingkang, Huang Jia and Lu Jun,2018).Interest rate liberalization has not been abandoned, and the interest rate still needs to be regulated (Yi Gang,2015).The ultimate goal of the interest rate market is not to liberalize interest rate control, but to enable financial institutions to have the ability to self-pricing. The mature financial market is the key premise for the complete liberalization of interest rates. After interest rate control is liberalized, on the one hand, the price of interest rate, risk management, corporate and governance should be cultivated, on the other hand, the market benchmark interest rate system should be improved(Hu Xinzhi and Yuan Jiang,2011).

From the perspective of the ecological environment of monetary policy transmission, equivalent to monetary policy shocks to the financial system and real economy, the impact mainly involves three main body and two links, namely, central Banks, financial institutions and the public (i.e., firms and households) three main body, from the central bank to financial institutions and financial institutions to the public two links (Wu Shiqiao,2014). The classical theory of interest rate transmission mechanism emphasizes the preconditions and results, that is, under certain initial preconditions, the corresponding interest rate transmission results are generated, because the interest rate transmission mechanism will automatically complete the whole transmission process.But in fact, the interest rate conduction ecosystem will be to make a positive response to input variables, since the policy interest rate into the conduction system of the moment, the interest rate transmission mechanism by which the condition may have changed, according to the rate of the premise condition may not be expected to conduct a result, therefore in the process of interest rate conduction game with market main body, promote the realization of conduction results by strengthening process control. This is an important reason why global central Banks have shifted their monetary policy from rules to discretion.

Mature interest rate regulation system generally consists of policy interest rate, operation target, intermediate target and ultimate target.After the completion of interest rate liberalization, the base currency is no longer suitable as the operational target of China's monetary policy, but should be gradually replaced by the short-term interest rate of the monetary market (GaoXingwei and Gu Muqing,2016). The international experience and practice of the monetary policy transition can also prove the importance of the short-term market interest rate. 
From the perspective of intermediary targets of monetary policies of developed countries, the 1980s was the era of narrow sense of money, the 1990s was the peg system, and the decade before the outbreak of the global financial crisis in 2008 was the inflation target system (Zhang Xiaojing and Dong Yun, 2013).After the global financial crisis, it is a hybrid target system, that is, both the inflation target system and the exchange rate target system. The ultimate goal of monetary policy is often inextricably linked to stabilizing prices and exchange rates, promoting economic growth and employment. Although China opened the interest rate corridor construction process in 2014 with the establishment of standing loan facilities, aiming to build a new interest rate transmission mechanism. However, the policy interest rate has not yet been clarified. In the actual operation of the People's Bank, the overnight interest rate of the interbank borrowing market the 7-day interest rate in the pledge repo market shows the function of policy interest rates.

In summary,although China's interest rate market reform has made great breakthroughs and progress, the interest rate transmission mechanism is not perfect and fragile, and there are still many obstacles blocking the interest rate transmission mechanism. The improvement of the interest rate transmission mechanism is a long-term battle, and it will not be completed once and for all.Only by plugging up, testing and innovating in the practice of interest rate regulation, and by holding, grasping and adapting to the situation in practice, can the interest rate transmission mechanism maintain its vitality forever.

At the same time, it also indicates that the interest rate transmission mechanism cannot be separated from the brewing soil of interest rate marketization reform. The policy dependence formed by China's long-term regulatory interest rate system cannot be completely removed in a short time, and the switch between the old and new systems and mechanisms needs to use certain strategies and paths.

Like the reform process of interest rate liberalization, the evolution of interest rate transmission mechanism has trace and inertia. The evolution of interest rate transmission mechanism is problem-oriented and takes the monetary policy effect as the criterion. The central task should be how to maintain the significant effectiveness of monetary policy in the context of the increasingly weak effect of quantitative monetary policy.From this point of view, it is of great necessity, significance and value to analyze and summarize the historical evolution of interest rate transmission mechanism.

\section{Interest rate transmission mechanism under the dual-track system}

China has long been in a dual-track interest rate system, and the market interest rate and deposit and loan interest rates have different interest rate policies.In the practice of interest rate market reform, the people's bank of China follows the principle of "first market interest rate, second loan interest rate, and later deposit interest rate".Considering that China's financial market has always been dominated by indirect financing, and the market interest rate has a great impact on the direct financing market and the fund wholesale market, and the deposit and loan interest rate has a great impact on the indirect financing market and the fund retail market, the guiding principle and principle of the people's bank of China to promote the interest rate liberalization reform is obvious.

In this process, the transmission mechanism of interest rates is quietly changing, and the leverage effect of interest rates is more obvious. Under the dual-track environment, the change of the interest rate transmission mechanism can be divided into two stages. The first stage is to establish the interbank market-oriented interest rate transmission mechanism, and the second stage is to explore the establishment of the deposit and loan market interest rate transmission mechanism.

\subsection{Establishing the interbank market interest rate transmission mechanism}

The inter-bank market is the first place to promote interest rate liberalization, and it also belongs to the capital wholesale market. The establishment of the inter-bank market interest rate transmission mechanism is gradually promoted in the context of the liberalization of market interest rates and the regulation of deposit and loan interest rates. From 1996 to 2014, the people's bank of China mainly promoted the market-oriented reform of money market interest rate, gradually removing a series of restrictions on market interest rate, and still implementing upper and lower limits on the deposit and loan interest rate of commercial Banks, but the upper limit of loan interest rate was gradually relaxed.The liberalization of the market interest rate means the cancellation of the upper and lower limits of the market interest rate. The market interest rate is subject to the changes in the supply and demand of funds in the market, which is initially manifested as the general rise of the market interest rate, and returns to the market forces driven by the longterm financial repression.Interest rate liberalization has greatly stimulated the vitality of the supply and demand of funds in the inter-bank market and improved the efficiency and level of market-oriented allocation of funds. The cultivation of market-oriented interest rate in the wholesale market other than deposit and loan has a direct impact on China's money market and bond market, and also lays a good foundation for China's market-oriented reform of deposit and loan interest rate. 
After first liberalizing the interbank lending market interest rate ceiling, in order to enhance the interest rate transmission mechanism, China gradually liberalized the repurchase market interest rate and the spot market rate, and extended the marketization of interest rates in an orderly manner to promote market interest rates by interbank lending. The market conducts to the repo market and the bond market, and uses market-based means to clear the transmission of interest rates, so that the market interest rate fully reflects the lack of funds of inter-bank institutions.At the same time, as a supporting measure, the people's bank of China changed the refinancing (rediscount) rate from a fixed rate to a floating rate, and adjusted the refinancing (rediscount) rate according to the supply and demand of the market to integrate the refinancing (rediscount) rate with the market rate, basically opening up the channel between the people's bank of China's interest rate system and the inter-bank market interest rate system.

Due to the decoupling between the interbank market interest rate and the interest rate of the deposit and loan market, and the small size and size of China's bond market at that time, although the market interest rate of the interbank interest rate once caused the market interest rate to rise once, it did not lead to the financing cost of the enterprise. Significant increase, not only the investment, consumption and import and export patterns have not been greatly affected, nor did it produce deflationary pressures, the impact on the real economy is limited, and China's industrial policy still played an expected supporting role.

However, due to the loan interest rate cap not completely let go, loan interest rate cannot fully reflect the credit supply and demand, the real interest rate is lower than the market supply and demand determine the real interest rate, loan from enterprise, the excess demand for loans and interest rates cannot effectively hedge the credit risk of small and medium-sized enterprises, hit the enthusiasm of commercial bank lending to small and medium-sized enterprises, small and medium-sized enterprise loan availability is not strong, in contrast, commercial Banks more willing to lend to large state-owned enterprises, despite the large state-owned enterprises implement the margin of interest rates to rise less than small and medium-sized enterprises, but large state-owned enterprises with the advantages of government endorsement, thus the risk is relatively low, Large amounts of loan funds are skewed and concentrated towards large state-owned enterprises.

To sum up, the inter-bank market interest rate and loan market interest rates to keep the certain independence, interbank market interest rates cannot effectively to the loan interest rates, in turn, the loan interest rates also inhibited the inter-bank market interest rate fluctuations.Under the control of commercial banks, due to risks and profits, the willingness to borrow is reduced, the scale of loans is declining, the liquidity of commercial banks is abundant, and the demand for funds in the interbank market is declining, thereby curbing the rise in interest rates in the interbank market.

\subsection{Exploring the establishment of interest rate transmission mechanism in the deposit and loan market}

From 2004 to 2015, the People's Bank of China actively explored the establishment of interest rate transmission mechanism in the deposit and loan market under the background that the loan interest rate is subject to the lower limit and the deposit interest rate is subject to the upper limit.In October 2004, the upper limit of loan interest rate and lower limit of deposit interest rate of commercial Banks were cancelled, and "lower limit of loan interest rate and upper limit of deposit interest rate were controlled" was implemented (Yi Gang,2009), until the lower limit of loan interest rate was cancelled in 2013 and the upper limit of deposit interest rate was cancelled in 2015.

After canceling the upper limit of commercial bank's interest rate on loans to enterprises,the policy of implementing different interest rate levels according to the nature and size of enterprise ownership is formally withdrawn.Commercial Banks can conduct market-oriented pricing according to the comprehensive credit of enterprises and households, and independently choose the floating range, so that the loan interest rate can more fully reflect the changes in the supply and demand of loan funds, and be more sensitive to the lack of liquidity in the inter-bank market, especially more conducive to commercial banks to provide credit support to SMEs.

Therefore, the inter-bank market interest rate is more likely to impact the loan market interest rate, and the correlation between the inter-bank market interest rate and the loan market interest rate is enhanced, and the transmission mechanism between the two is more perfect.This also shows that the improvement of the internal interest rate transmission mechanism in the loan market can promote the interconnection of the interest rate transmission mechanism between the inter-bank market and the loan market. As an important terminal market, the market-oriented interest rate formation mechanism is an important condition to enhance the interest rate transmission mechanism.

At the same time, controlling the upper limit of deposit interest rates, it can avoid the vicious price competition between commercial banks due to deposits, curb the impulse of excessive expansion of commercial banks, and prevent risks that threaten financial stability. However, the cap on deposit rates restricts the flow of funds to commercial bankswith high efficiency in management operations.Deposit is an important funding channel for loans. 
Under the constraint of the upper limit of deposit interest rate, deposit interest rate tends to be homogenized among different commercial Banks. The interest rate advantage of efficient Banks cannot be reflected in the capital retail market, so they are forced to obtain funds through the inter-bank lending market.

Part of the funds flowed to high-efficiency banks with low-efficiency banks as a bridge, increasing the flow of deposit funds to high-efficiency banks, so that deposit funds that could flow directly to high-efficiency banks were diverted to the interbank borrowing market, and then the interbank borrowing market flowed to high efficiency. The bank, in turn, transformed the high-efficiency bank's lending relationship with the private sector into a loan relationship between commercial banks and commercial banks, which lengthened the chain of interest rate transmission and increased the complexity of the interest rate transmission mechanism.

\section{Interest rate transmission mechanism under the merger}

In 2015, the people's bank of China abolished the upper limit of deposit interest rate, which was an important milestone in the process of China's interest rate liberalization reform, and made a big step forward on the path of integrating the benchmark interest rate of China's money market with the benchmark interest rate of deposits and loans.

So far, the regulation of money market interest rate and deposit and loan market interest rate has been abolished, which provides an important basis for the realization of the integration of money market interest rate and loan market interest rate.However, it is worth noting that the people's bank of China still retains the benchmark interest rates for deposits and loans, which are still playing the role of benchmark interest rates in fact.This institutional arrangement fully considers the actual situation of China's financial market, which is in line with the actual needs of China's monetary policy regulation, but also has an important impact on China's interest rate transmission mechanism.

\subsection{Establish a unified market-based interest rate transmission mechanism}

Since the cancellation of the deposit interest rate ceiling in 2015, he evolution of China's interest rate transmission mechanism has been driven mainly by two major forces. First, the upper and lower limits of deposit and loan interest rates have been completely abolished, and the barriers to interest rate liberalization have been further clarified in the interest rate policy system. It has created a market environment for the market formation, transmission and regulation of money market interest rates, bond market interest rates, and deposit and loan interest rates.Second, the benchmark interest rates of deposit and loan are still retained. Therefore, the benchmark interest rates of deposit and loan still have substantial influence on the deposit and loan market, and objectively there are restrictions on the benchmark interest rates of shadow deposit and loan.

Under this background, $\mathrm{t}$ there are two mechanisms for the money market interest rate to transfer to the deposit and loan interest rate. One mechanism is that the money market interest rate promotes the transmission of interest rates by affecting the money supply of the bond market and the deposit and loan market, that is, the rise and fall of the money market interest rate leads to funds. Substitution and diversion effects are generated in the bond market and the deposit and loan market.For example, when the money market interest rate is lowered and the bond yield is reduced, commercial banks will reduce the investment in bonds in asset allocation, and will invest more money in the loan market. The asset allocation of residents will also choose to save, and the savings will increase. The willingness of commercial banks to increase loans will increase the amount of funds that can be borrowed, and thus the supply of funds in the loan market will increase, and the interest rate on loans will decrease.

Similarly, if the money market interest rate rises, the bond yield will increase, which will induce residents to reduce their savings and purchase funds for bond products. At this time, commercial banks will also increase their investment in bonds, and thus the demand for funds will increase, but the savings of residents will decrease. This means a reduction in the supply of deposit funds, while commercial banks have increased demand for savings funds, which has led to an increase in deposit rates.

Another transmission mechanism from money market interest rate to deposit and loan interest rate is that deposit and loan interest rate directly connects with money market interest rate. When the short-term interest rate in the money market as the benchmark interest rate changes, the benchmark interest rate of different maturity changes under the arbitrage, and then the benchmark yield curve is formed. The financial institution combines the actual situation and the benchmark interest rate on the money market. The deposit and loan interest rate is up and down, and the deposit and loan interest rate is in line with the marketization of the money market interest rate.It is equivalent to the benchmark interest rate of the money market acting as the benchmark interest rate of deposits and loans. Financial institutions themselves have the ability to set prices independently and are no longer dependent on the benchmark interest rate of deposits and loans determined by the people's bank of China, thus decoupling from it.Of course, there are certain conditions to achieve this. Since the establishment of SHIBOR in 2007, the construction of money market benchmark interest rate system has been gradually improved. 
In essence, SHIBOR is an unsecured financing rate including risk premium, which is different from the bond pledged repo rate based on the mortgage guarantee, which is almost risk-free. For this reason, SHIBOR is often higher than the bond pledged repo rate. With the further development of derivative markets such as interest rate swap market, the mechanism of SHIBOR's benchmark extending to deposit and loan interest rate is increasingly mature.

However, since the People's Bank of China has not completely canceled the deposit and loan benchmark interest rate, SHIBOR has not yet fully been able to serve as the benchmark interest rate for the deposit and loan market. The deposit and loan interest rate is directly linked to SHIBOR and is still in the process of cultivating and guiding. The deposit and loan interest rate directly links the transmission mechanism of SHIBOR. It has not really played a role, and most banks are still reluctant to adopt market interest rates as the pricing basis for deposit and loan interest rates (Ma Jun, Ji Min,2016).

On the contrary, the first kind of conduction mechanism of the effect is more apparent, and the first transmission mechanism in before cancel lower limit controls on lending and deposit rates, has been developing with Unicom deposit and lending rates and the role of monetary market interest rate, the transmission mechanism by influencing the loanable funds to affect interest rates, in essence not only embodies the interest rate transmission mechanism, more embodies the credit mechanism, in the case of interest rates transmission mechanism block, however, the credit mechanism is likely to remain open. With the integration of money market interest rate and deposit and loan interest rate, the benchmark deposit and loan interest rate fades out, and the transmission mechanism will gradually weaken.

\subsection{Future evolution direction of interest rate transmission mechanism}

From the experience of foreign developed economies, as the interest rate marketization environment continues to mature and improve, the benchmark interest rates for deposits and loans will gradually withdraw from the stage. The benchmark interest rates of the money market and the benchmark interest rates for deposits and loans will be truly integrate,the interest rate transmission mechanism in the perfect market benchmark interest rate system and the financial derivatives with matching support more unobstructed.Only by continuously enhancing the adaptability and immunity of the market players themselves can we improve the sustainability and effectiveness of the interest rate transmission mechanism.

At present, China's interest rate marketization reform and interest rate transmission mechanism construction need to continue to push forward, get through the last kilometer, solve the key problems.From the perspective of the problems restricting the interest rate transmission mechanism in China, it mainly includes two aspects, namely, improving the benchmark interest rate system of the money market and enhancing the pricing power of financial institutions, which are embodied in the following aspects:

China's money market benchmark interest rate system is not yet mature. Although the Shanghai Interbank Offered Rate (SHIBOR) has been officially launched since January 2007, it has become the market-recognized and most widely used benchmark interest rate (Xu Lin and Zhang Bixin,2017).

However, under the background that the new policy target interest rate is not yet clear, the policy direction of the people's bank of China taking the 7-day repo rate as the target interest rate is becoming increasingly obvious. The standing lending facility (SLF) has shifted from the overnight interest rate to the 7-day repo rate (XuZhong and Li Hongjin,2019).Before 2007, the inter-bank offered rate was the key money market interest rate cultivated in China.In recent years,interbank bond repo market has developed rapidly, and the buyback operation has gradually become the main tool of regulation of the people's bank of liquidity (Ba Shusongand Shang Hangfei,2015).Empirical research shows that there is a pass-through relationship between the interbank bond repo market and the interbank lending market, and the repo rate has a great influence on the SHIBOR, but the reverse effect is weak (Fan Lifu,Zhou Jiyan and Wang Quan,2015).SAs the benchmark interest rate of China's money market, SHIBOR still has great uncertainty, and it cannot completely become the pricing basis of other interest rates in China's financial market (Liu Yisheng and Wang Chunli,2018).

In addition, the people's bank of China still maintains the benchmark interest rate of deposits and loans. Data shows that the lending rate is still mainly tracking the benchmark interest rate of loans rather than the money market interest rate. Since 2008, the benchmark lending rate is still the most important factor affecting the weighted average lending rate of financial institutions in China (GuoYumei,Dai Ze and PengYuchao, 2018).Through interest rate agreements between large commercial Banks, the deposit rate has actually only risen to 1.4-1.5 times the benchmark rate (Zhao Shengmin and Chen Qian,2019). The interest rate pricing power of financial institutions is still not enough to effectively support the smooth transmission of interest rates. The dual structure and shadow banking business of China's banking system has reduced the role of external factors in bank interest rate determination, and to some extent reduced the effectiveness of interest rate marketization reform (Liu Mingkang, Huang Jia and Lu Jun,2018). 
Before 2008, interest rate transmission channels of China's monetary policies were not smooth, and monetary policies mainly affected the real economy through credit channels (Sheng Songcheng and Wu Peixin,2008).

Since 2008, the quantitative monetary policy regulation efficiency drops, and gradually increase the effectiveness of the interest rates (Xiang Weixing and Li Hongjin,2012), but because of the commercial bank interest rate pricing within the "double track" characteristics of money market interest rates to the loan interest rate conduction is still not free (GuoYumei, Dai Ze, and Peng Yuchao,2018).The interest rate stickiness of China's financial market is still high, and there is a weak lag relationship between money market interest rate and commercial bank loan interest rate (Zhou Yuan and Chen $\mathrm{Yu}, 2016)$.

Moreover, the pricing methods of loan interest rates of large and small commercial Banks are different. Large commercial Banks will adopt competitive pricing strategies, and small commercial Banks will pay more attention to developing relational lending (ZengYiliang, Wang Yanan, Zhang Dingsheng and Fu Qiang,2019).

The bond market and the banking system are the important places where the interest rate transmission mechanism comes into being and evolves. The transmission of the money market interest rate to the bond market interest rate and the deposit and loan interest rate is the general direction, which can reflect the transmission process from the short-term interest rate to the medium and long-term interest rate, as well as the transmission process from the financial system to the real economy.After years of reform and evolution, the transmission mechanism of money market interest rate to bond market interest rate is gradually mature, while the transmission mechanism of money market interest rate to deposit and loan interest rate is still evolving, which is closely related to the weak pricing power of Chinese financial institutions and the imperfect market benchmark interest rate system.

At the same time, long-term dependence on the benchmark interest rate of deposit and loan announced by the people's bank of China has become an obstacle to the continuous evolution of the interest rate transmission mechanism in China, and also lays a foreshadowing for the optimization and improvement of the interest rate transmission mechanism in the future.

\section{Revelation}

With the reform of interest rate marketization, China's interest rate transmission mechanism has undergone profound changes. It is characterized by the combination of reality, gradual progress and great achievements. In international practice, China has set a model for the reform of interest rate marketization and the construction of interest rate transmission mechanism. Standing at the new starting point of improving the interest rate transmission mechanism in China, we still need to continue to strengthen the weak points and solve the bottleneck problems in the process of interest rate transmission.Along the logical track of history, We can get the following inspirations.

1) The establishment and improvement of the interest rate transmission mechanism needs to exert the power of "government and market".Monetary policy can fully reflect the common strength of the visible hand of the "government" and the invisible hand of the "market". The smooth flow of the interest rate transmission mechanism cannot be separated from the integration of the two mechanisms, and the effectiveness of the interest rate transmission mechanism will be greatly weakened by the failure of either force alone.The more perfect the interest rate transmission mechanism is, the more market-oriented the means and means of regulating interest rate will be, which can improve the long-term effectiveness and reliability of the interest rate transmission mechanism.

In turn, only the power of the market can effectively support the effective and smooth flow of interest rate transmission mechanism. If the market forces are allowed to form and regulate interest rates, it may produce adverse selection, causing uncontrollable imbalances in the market itself and rapidly accumulating a large number of risks, causing large fluctuations in interest rates, jeopardizing the stability and health of the financial market.The particularity of the interest rate transmission mechanism determines the need for the double-wheel drive of "government" and "market", which should be organically bundled. The people's bank of China should regulate the market, and the market should regulate the main body of the financial market, so as to give full play to the overall synergy and form a well-structured and logically unified interest rate transmission mechanism.

2) We should further improve the mechanism for regulating interest rates in the money market.Money market interest rate plays an important role in the effective operation of interest rate transmission mechanism.Money market interest rate is an important tool for people's bank of China to implement interest rate regulation, and a common starting point for interest rate transmission to bond market.

In addition, money market interest rate is the key basis of market benchmark interest rate. The mature and perfect interest rate transmission mechanism first means the perfect monetary market interest rate control mechanism. 
Reasonably controlling the interest rate in the monetary market equals to holding the "cow nose" and the general valve of the interest rate transmission mechanism.If the interest rate transmission mechanism is regarded as a lock, then the interest rate control mechanism is the key to unlock the lock.

3) We will vigorously develop the bond market and improve its role in the interest rate transmission mechanism.In order to fully highlight the advantages of the transmission mechanism of market interest rate on the bond market, we should continue to vigorously develop the bond market, innovate the bond financing products, perfect the risk control mechanism, create a bond financing tool in line with the actual situation of small and medium-sized enterprises, and improve the availability of bond financing for small and medium-sized enterprises.

At the same time, we should expand the scope of bond collateral of the People's Bank of China's standing lending facility, and medium-term lending facility and other tools, enhance the liquidity of bond financing products, and finally actively attract enterprises to make full use of bond financing mode, and improve the effectiveness of the mechanism of the transmission of the policy interest rate of the people's bank of China to the interest rate of different maturities.

\section{References}

Wan Quan, and Sun Bin.(2012)Interest Rate Marketization Reform: Comparison and Reference.Contemporary Economic Research,5,71-74.

Fan Fangzhi.(2006)Review and prospect of China's interest rate market reform.Journal of the Party School of the CPC Changchun Municipal Committee,4,37-39.

ShenQiyun, and Wen Ming.(2004)System, gradual transition and China's interest rate liberalization reform.Jinan financial,5,6-8.

Zhao Shengmin, and Chen Qian.(2019)The transmission effect of monetary policy credit channels in the process of interest rate liberalization.Contemporary Economic Sciences, 4,1-13.

Chen Yulu.(2018)Guide financial resources to the efficient sectors of the real economy.Chinese SMEs,12,13.

Liu Mingkang, and Huang Jia, and Lu Jun.(2018)Bank interest rate decision and internal capital transfer pricing -- from the experience of China's interest rate liberalization reform.Economic Research,6,4-20.

Yi Gang.(2015)Interest rate marketization is not released, it still needs regulation.Selected international monetary and finance daily review in 2015.

Hu Xinzhi, and Yuan Jiang.(2011)Progressive reform: the rational choice of interest rate liberalization in China -- the international experience of interest rate liberalization and its enlightenment to China.International economic review, 6,132-145.

Wu Shiqiao.(2014)The evolution and enlightenment of the monetary policy framework of the bank of Japan after the financial crisis.Japanese problem research,3,19-26.

GaoXingwei, and GuMuqing.(2016)The influence of interest rate liberalization on the operational objectives of China's monetary policy.Science of finance and economics,12,35-46.

Zhang Xiaojing, and Dong Jun.(2013)Reconstructing macroeconomic policy framework: exploration and debate. Comparative Studies,3,17-21.

Yi Gang.Three decades of reform and opening up in China's interest rate liberalization process. Economic Research, 1,1-14.

Ma Jun, and Ji Min.(2016)Interest rate transmission mechanism under the framework of new monetary policy. Beijing:China Financial Publishing House.

$\mathrm{Xu}$ Lin, and Zhang Bixin.(2017)Evaluation and research on the effect of the reform of the quotation mechanism of Shanghai interbank offered rate.Price theory and practice, 6,122-125.

XuZhong, and Li Hongjin.(2019)The term selection of policy target interest rate under the mode of monetary price control. Studies of International Finance,3,3-12.

Ba Shusong, and Shang Hangfei.(2015) The Evolution, Practice and Enlightenment of the Regulation Mode of Interest Rate Corridor. Modern Economic Research,5,5-10.

Fan Lifu, Zhou Jiyan, and Wang Quan.(2015)Study on the linkage effect between repo rate and SHIBOR. Macroeconomics, 7,80-87.

Liu Yisheng, and Wang Chunli.(2018)SHIBOR's status, characteristics and interest rate corridor construction. Jianghan Tribune, 2,24-29.

GuoYumei, Dai Ze, and PengYuchao.(2018)Research on the transmission efficiency of China's monetary policy interest rate: 2008-2017.Journal of Finance Research,12,37-54.

Sheng Songcheng, and Wu Peixin.(2008)The Dual Transmission Mechanism of China's Monetary Policy: A Study of the Model of "Two Intermediary Targets and Two Control Objects". Economic Research,10,37-51. 
Xiang Weixing, and Li Hongjin.(2012) Challenges and transformation direction of quantitative monetary control faced by the central bank of China. Studies of International Finance, 7,20-28.

Zhou Yuan, and Chen Ji.(2016)Study on interest rate stickiness in China's financial market -- based on random fluctuation model analysis of time-varying parameters. Journal of Xinjiang University, 9,1-7.

ZengYiliang, Wang Yanan, Zhang Dingsheng, and Fu Qiang.(2019)Commercial bank size and loan rate pricing under asymmetric information. Journal of Central University of Finance \& Economics, 1,23-36.

Song Fangxiu, and Gong Ying.(2018)Study on the effect of standing lending facility interest rate as the upper limit of interest rate corridor. Economic Review Journal,12,69-87. 